\title{
POLÍTICAS E DESAFIOS DO ENSINO BÁSICO NO SISTEMA NACIONAL DE EDUCAÇÃO MOÇAMBICANA
}

\author{
BASIC EDUCATION POLICIES AND CHALLENGES IN THE NATIONAL MOZAMBICAN \\ EDUCATION SYSTEM
}

\author{
Augusto Kessai Agostinho Chicava \\ Universidade Federal do Rio Grande do Sul, Porto Alegre, RS, Brasil. E-mail: augustochicava@yahoo. \\ com.br
}

\section{Odilia Alberto Cumbi Machama}

Direção de Educação de Moçambique, Moçambique, África E-mail: odymac@gmail.com

\section{DOI: https://doi.org/10.46550/amormundi.v1i2.2}

Recebido em: 01.09.2020

Aceito em: 13.10.2020

\begin{abstract}
Resumo: O objetivo principal do estudo é refletir em torno de políticas e desafios do ensino básico no sistema nacional de educação Moçambicana, no período pós-independência, a partir das transformaçôes socioeconómicas e políticas. O estudo adota uma pesquisa bibliográfica e documental, a partir legislação educacional moçambicana. E, conclui-se que as políticas do ensino básico ainda está preocupado em oferecer o ensino de qualidade, mas os desafios como a insuficiência no provimento de professores; inadaptação dos currículos às atuais necessidades do mercado de trabalho, e orçamentos insuficientes, de desistência de alunos nas escolas constitui um calcanhar de aquiles.
\end{abstract}

Palavras-chave: Políticas. Desafios. Ensino Básico. Moçambique.

\begin{abstract}
The main objective of the study is to reflect on the policies and challenges of basic education in the national Mozambican education system, in the post-independence period, based on socio-economic and political transformations. The study adopts bibliographic and documentary research, based on Mozambican educational legislation. And, he concluded that basic education policies are still concerned with offering quality education, but with challenges such as insufficient teacher supply; unsuitability of curricula to the current needs of the labor market, and insufficient budgets, high repetition rates, dropping out of students in schools is an Achilles' heel.
\end{abstract}

Keywords: Policies. Challenges. Basic education. Mozambique.

\section{Introduçáo}

$\mathrm{D}$

epois da independência, da guerra civil e das eleiçôes de 1994, a educação foi encarada como uma prioridade nacional, com destaque para o ensino elementar. 
O sistema educativo nacional moçambicano ${ }^{1}$ era regulado por uma Lei de bases, de 1983, a lei constituía uma das principais conquistas da educação pós-colonial, pois este procurava traduzir na prática o tipo de sociedade que se pretendia construir e que papel seria reservado à educação nessa gigantesca missão (CHICAVA, 2018).

A introdução do sistema nacional de educação em 1983, tinha como objetivo;

a erradicação do analfabetismo, a introdução da escolaridade obrigatória e a formação de quadros para o desenvolvimento económico e social e da investigaçáo científica, tecnológica e cultural [...] um maior conhecimento do universo cultural e psicológico do aluno, uma nova estratégia na formação de professores, uma investigação pedagógica aprofundada que permita utilizar metodologias de ensino e critérios de avaliação eficazes, bem como elaborar programas e manuais de ensino adequados (Moçambique, 1983, p. 15).

Em 1992 o Sistema Nacional de Educação moçambicana foi reajustado (Moçambique, 1992) de modo a refletir as transformaçôes socioecónomicas e políticas de cariz neoliberal advindas da adopçáo do Programa de ajustamento estrutural nos finais dos anos 80 do século passado e a introduçáo de uma nova Constituição em 1990 (Moçambique, 1990), marcando o fim do modelo de economia centralmente planificada e sob a égide de um partido único, o Partido Frelimo (STELA DUARTE et al, 2019).

Em Agosto de 1995, foi aprovada pelo Governo uma nova política nacional de educação, reconfirmada pelo "Plano Nacional de Desenvolvimento do Sistema Educativo", discutido com os doadores em Setembro de 1997, em que se definiram as grandes orientaçóes para os anos vindouros, a saber: melhorar o acesso à educação e a qualidade do ensino, isto é, "combate ao insucesso escolar através da reforma curricular de modo a tornar o currículo mais relevante e flexível” (MINED, 1995, p. 8-9).

O sector da Educação em Moçambique, particularmente do ensino básico, enfrenta vários desafios, dentre os quais, melhorar a qualidade do ensino através do aumento das habilidades de leitura, escrita e cálculo numérico nos ciclos iniciais para alcançar uma escolarização de 9 anos no ensino básico, assegurando um equilíbrio entre a qualidade e a expansão do ensino.

É neste âmbito que se encontrou duas abordagens distintas, mas com o mesmo foco. A primeira abordagem tem como objetivo buscar melhores estratégias para expandir o acesso quantitativo do ensino básico. Esta visão tem como referência de partida uma expansão quantitativa de infraestruturas escolares, inspirados no âmbito do plano de educação básica para todos. A segunda discute e póe em causa a qualidade da educação básica. Neste, os argumentos apontam na necessidade de olhar para a avaliaçáo no seu todo, ao invés de diagnosticar os alunos sob uma e única perspectiva de avaliação-sumativa.

No quadro dos objetivos do ensino básico foram definidas metas ambiciosas, tais como garantir que todas as crianças ingressem entre 6 ou 7 anos de idade e que concluam os nove anos de escolaridade e melhorar a fraca qualidade do ensino manifestado através de um melhor

1 O Sistema Nacional de Educação (SNE) de Moçambique é concebido no quadro do plano Prospectivo Indicativo (PPI) elaborado pelo Governo de Moçambique em 1980. O PPI tem como objetivo fundamental "eliminar o subdesenvolvimento" na década (1980-1990). A eliminação do subdesenvolvimento significa, na óptica do Governo, um "grande salto" em direção ao Socialismo. No contexto desta utopia social, à educação (formal) cabe jogar um papel importante, senão mesmo central, porque é vista como o eixo da formação humana. $\mathrm{Na}$ altura, para o desenvolvimento acelerado, opta-se por uma planificaçáo centralizada e por grandes investimentos (CASTIANO e NGOENHA, 2013, p. 80-81). 
desempenho dos alunos no que concerne à aquisição de competências básicas.

E, é comum no ensino básico sistema de educação moçambicana priorizar a avaliação numa e única dimensão, ou seja, fazer juízo de valor aos alunos através dos resultados, sem olhar o objectivo principal da avaliação que é interrogar, buscar os conhecimentos construídos e as dificuldades que cada aluno apresenta. A avaliação, no contexto do ensino básico no sistema de educação moçambicana, é uma prática educativa geradora de muitos problemas, dificuldades e serve de meio para selecionar os alunos, provocando desta maneira o despedimento massivo dos alunos no ensino através das reprovaçôes.

\section{Políticas do ensino básico: educação solidária e desenvolvimento humano}

A base jurídica do Sistema Nacional de Educação de Moçambique que determina os princípios, funçôes e objetivos de cada subsistema de ensino, incluindo o primário, foi emanada por Lei no 18/2018 de 28 de Dezembro², que confere a educação básica competências fundamentais à criança, jovem e adulto para o exercício da cidadania, fornecendo-lhes conhecimento geral sobre o mundo que os rodeia e meios para progredir no trabalho e na aprendizagem ao longo da vida" (MOÇAMBIQUE, 2018, p. 21).

A lei anteriormente referida revoga a lei no 6/92, de 06 de Maio que divide o Sistema de Educação em cinco subsistemas, e requalifica a estrutura básica do Sistema de Educação em Moçambique, em 3 subsistemas fundamentais: ensino pré-escolar, ensino escolar e ensino extraescolar, a Lei no 18/2018 diz que a educação básica compreende o ensino primário e primeiro ciclo do ensino secundário.

O ensino pré-escolar é atualmente oferecido por creches e escolinhas do Ministério do Género, da Criança e da Ação Social (MGCAS), organizaçôes não-governamentais (ONG's), organizaçóes comunitárias, religiosas e sector privado. Este subsistema tutelado pelo MGCAS é repartido em dois níveis: Nível das creches onde frequentam as crianças dos 2 meses aos 2 anos e o nível dos jardins-de-infância, onde frequentam crianças dos 3 aos 5 anos, no entanto este subsistema não é obrigatório.

Segundo lei 18/2018 no seu artigo $9^{\circ}$, o Sistema Nacional de Educação moçambicana é constituído pelos seguintes subsistemas: Subsistema de Educação Pré-Escolar; Educação Geral; Educação Geral; Educação de Adultos; Educação Profissional; Educação e Formação de Professores e Ensino Superior. E, O ensino primário (EP) é constituído por 7 anos de escolaridade, repartidos por dois níveis: $\mathrm{O}$ primeiro nível, designado por EP1, abrange as crianças da $1^{\text {a }}$ a $5^{\text {a }}$ séries, na faixa etária dos 6 aos 10 anos de idade e o segundo nível designado EP2 que compreende a $6^{\mathrm{a}}$ e $7^{\mathrm{a}}$ séries frequentado por crianças que se encontram na faixa etária dos 11 a 12 anos de idade.

Em 2004, o Ministério da Educação (MINED) introduziu o novo currículo, o EP foi reformado com o intuito de melhorar alguns pontos críticos do subsistema e, a sua estrutura dividiu-se em 3 ciclos de aprendizagem numa perspectiva de oferecer um ensino básico obrigatório de nove anos: o $1^{\mathrm{o}}$ ciclo ( $1^{\mathrm{a}}$ e $3^{\mathrm{a}}$ séries), o $2^{\mathrm{o}}$ ciclo (4 $4^{\mathrm{a}}$ e $6^{\mathrm{a}}$ séries) e o $3^{\mathrm{o}}$ ciclo (7a e $9^{\mathrm{a}}$ séries).

A idade oficial de ingresso na $1^{\text {a }}$ série é de 6 anos, ou seja, " a criança deve ser

2 Lei vigente no Sistema Nacional de Educação de Moçambique. 
obrigatoriamente matriculada na $1^{\text {a }}$ classe (série), até 30 de junho, no ano em que completa 6 anos de idade" (MOÇAMBIQUE, 2018, p. 13). Assim, os dois níveis do ensino básico estão a ser ultimamente associados numa única série (Ensino Primário Completo - EPC) que é composta por um ciclo de 6 anos de ensino primário.

O Ensino Primário joga um papel importante no processo de socialização das crianças, na transmissão de conhecimentos fundamentais como a leitura, a escrita e o cálculo e de experiências comumente aceites pela nossa sociedade (MINED, 2003). E, o ensino primário tem como objetivos:

a) proporcionar uma formação inicial nas áreas da comunicação, ciências sociais, ciências naturais, matemática, educação física, estética e cultura; b) desenvolver conhecimento socialmente relevantes, técnicas básicas e aptidóes de trabalho manual, atitudes e conviç̧óes que proporcionem maior participação social para o ingresso na vida produtiva (MOCAMBIQUE, 2018, p. 21).

As escolas primárias funcionam normalmente em dois turnos de 6 tempos lectivos, um no período da manhã e outro no período da tarde. Para acomodar a expansão do sistema, ou seja, garantir o maior número de ingressos no sistema e, tendo em conta a insuficiência de infraestruturas, algumas escolas primárias, sobretudo nas zonas urbanas, funcionam em três turnos de 5 tempos lectivos ( 40 minutos). Esse ensino realiza-se em duas modalidades: monolingue, em língua portuguesa e bilingue em uma língua moçambicana, incluindo a língua de sinais e em língua portuguesa (MOÇAMBIQUE, 2018, p. 21).

Para aliviar a pressão exercida em termos de ingresso no EP1, algumas escolas do EP1 leccionam também o EP2 no curso noturno. Mais ou menos 2\% de alunos frequentam o ensino primário em escolas privadas, comunitárias ou religiosas. Depois de concluir o EP, os alunos podem continuar os estudos no ensino secundário ou ensino técnico-profissional de nível básico (MINED, 2012, p. 20).

Assim, as políticas da educação do ensino básico no sistema de educação moçambicana estão voltadas à inclusão, à formação e à preparação do capital humano, e considera a necessidade de estender rapidamente as oportunidades educativas e garantir um ensino de qualidade, isto é;

[...] a Política Nacional de Educação é de assegurar o acesso à educação a um número cada vez maior de utentes e de melhorar a qualidade dos serviços prestados em todos os níveis e tipos de ensino. Portanto, pretende-se massificar o acesso da população à educaçấo e fornecer uma educação com uma qualidade aceitável, isto é, uma educação com um conteúdo apropriado e um processo de ensinoaprendizagem que promova a evolução contínua dos conhecimentos, habilidades, atitudes e valores, de modo a satisfazer os anseios da sociedade (MINED, 1995, p. 15).

A Educação Básica é de importância fundamental para a estratégia de desenvolvimento do país, porque: é um elemento central de estratégia da reduçáo da pobreza, uma vez que, por um lado, a aquisição de conhecimentos académicos, incluindo a alfabetização de adultos, irá alargar as oportunidades de acesso ao emprego, auto-emprego e aos meios de subsistência sustentáveis ao cidadão moçambicano e, por outro, aumentar a equidade do sistema educativo; assegura o desenvolvimento dos recursos humanos, base para o sucesso da economia nacional; é uma necessidade para o efetivo exercício da cidadania (MINED, 2003).

Neste contexto constituem principais objetivos do ensino básico, os seguintes 
pressupostos: a) Assegurar que todas as crianças ingressem no ensino na idade certa (6 ou 7 anos) e que permaneçam até complementar 7 anos de escolaridade; b) Melhorar a qualidade de ensino expresso pelo desempenho escolar dos alunos, sobretudo no que se refere às competências de leitura, escrita, cálculo numérico e o reforço da capacidade institucional (MINED, 2014, p. 1), ou ainda;

a) Proporcionar à criança um desenvolvimento integral e harmonioso; b) Capacitar a criança, o jovem e o adulto com um conjunto de padróes de conduta, que o tornarão um membro ativo e exemplar na sua comunidade e um cidadáo responsável na sociedade; c) Capacitar a criança, o jovem e o adulto para desenvolver valores e atitudes positivas para a sociedade em que vive; d) Dar à criança, ao jovem e ao adulto a oportunidade de apreciar a sua cultura, incluindo a língua, tradiçóes e padróes de comportamento; e) Garantir que a criança, o jovem e o adulto conheçam o meio em que vivem, isto é, conheçam as leis da natureza, a sua comunidade, o país e o mundo; f) Ajudar a criança, o jovem e o adulto a desenvolver plenamente as suas potencialidades; g) Encorajar a criança, o jovem e o adulto para observar, refletir e desenvolver um sentido de crescente autonomia e autoestima; h) Desenvolver a imaginação, a criatividade e o gosto pelas artes (MINED, 2003, p. 20).

E um dos subsistema do ensino básico é educação geral, que é o eixo central do Sistema Nacional de Educação, e, tem como objetivos:

a) proporcionar o acesso ao ensino de base ao cidadão, contribuindo de modo a garantir a igualdade de oportunidade de acesso aos sucessivos níveis de ensino e ao trabalho; b) garantir uma formação integral ao cidadão para que adquira e desenvolva conhecimento e capacidades intelectuais, físicas e uma educação estética e ética; c) assegurar uma formação que responda as necessidades materiais e culturais do desenvolvimento económico e social do país; d) detectar e incentivar aptidóes, habilidades e capacidades especiais, nomeadamente, intelectuais, técnicas, artísticas, desportivas e outras (MOCAMBIQUE, 2018, p. 21).

Para a concretização dos objetivos acima expressos, o subsistema do ensino básico nos últimos anos, tem vindo a adoptar várias estratégias, como a introdução do novo currículo, construção acelerada de escolas, descentralização da gestão dos fundos para as escolas, formação e capacitação dos professores, distribuição gratuita do livro escolar, supervisão pedagógica, monitoria e avaliação do desempenho.

Apesar dos esforços empreendidos para melhorar os indicadores negativos que afetam a educação básica, verificam-se ainda muitos problemas. Por exemplo, no que tange ao aproveitamento pedagógico dos alunos registou-se um declínio desde 2008, comparando aos anos anteriores. Há ainda crianças que no fim do $1^{\circ}$ ciclo, do ensino básico ( $3^{\mathrm{a}}$ séries) apresentam dificuldades de leitura e escrita. Neste sentido, há uma percepção generalizada, segundo a qual, a qualidade do ensino é fraca e questiona-se as competências dos professores e a validade dos métodos usados na sala de aulas.

\section{Os desafios no ensino básico no sistema nacional da educaçáo moçambicana}

O sector da Educação em Moçambique, particularmente do ensino básico, enfrenta vários desafios, dentre os quais, melhorar a qualidade do ensino através do aumento das habilidades de leitura, escrita e cálculo numérico nos ciclos iniciais para alcançar uma escolarização de 9 anos 
no ensino básico, assegurando um equilíbrio entre a qualidade e a expansão do ensino.

É neste âmbito que se encontrou duas abordagens distintas, mas com o mesmo foco. A primeira abordagem tem como objetivo buscar melhores estratégias para expandir o acesso quantitativo do ensino básico. Esta visão tem como referência de partida uma expansão quantitativa de infraestruturas escolares, inspirados no âmbito do plano de educação básica para todos.

De acordo com o programado nos Objetivos de Desenvolvimento do Milénio, todas as crianças em idade escolar deveriam frequentar o ensino básico de qualidade, o que significa que Moçambique deveria alcançar a escolaridade primária universal até 2015 (ONU, 2013, p. 14). A universalização do ensino primário atingiu $80 \%$ de crianças em idade escolar, o que significa, em termos práticos que, em cada 100 crianças moçambicanas em idade escolar, somente 80 crianças são escolarizadas e as restantes não usufruem o direito à educação consagrado na constituição de 2004. Não tendo alcançado os objetivos do milénio, quais seriam as razóes que concorrem para o não alcance dos mesmos?

Apesar de mais de 6 milhóes de alunos, dos 6 aos 12 anos, estarem a frequentar o ensino primário, ainda há crianças em idade escolar que não frequentam a escola (JORNAL O PAÍS, 2014, p. 12), Castiano e Ngoenha reafirmam esta tese, sustentando que;

o sistema formal de ensino não consegue absorver todas as crianças em idade escolar deixando de fora cerca de $50 \%$ das crianças pois verifica-se ainda a insuficiência de infraestruturas, o que constitui uma fonte permanente e sistémico de crescimento da população analfabeta no país" (CASTIANO e NGOENHA, 2013, p. 173).

E umas das razões (outra razão) a situação da falta de infraestruturas, mas as autoridades estatais têm envidado esforços no sentido de construir mais escolas e salas de aulas, o que possibilita o aumento de números de alunos no sistema nacional de educaçáo (SNE) e minimiza o problema da superlotação nas salas de aulas, de forma a garantir que todas as crianças tenham a oportunidade de completar o ensino primário.

De acordo com o Relatório de Desempenho do Sector da Educação publicado no Jornal "O País", para o ensino primário considerado prioritário pelo Governo, foram construídas nos últimos cinco anos mais de 1.200 escolas do $1^{\circ}$ grau. E no que refere-se ao acesso, o ensino básico do $1^{\circ}$ grau compreendia em 2010, um total de 10.444 escolas, frequentadas por 4.456 .585 alunos. Em 2014, o número de escolas era de 11.742, sendo frequentadas por 4.857 .259 alunos $^{3}$ (JORNAL O PAÍS, 2014 p. 4).

No $2^{\circ}$ grau do ensino básico, o número de instituiçôes subiu $70 \%$ e atualmente conta com um total de 5.086, contra as anteriores 2.999 (JORNAL O PAÍS, 2014 p. 2). Como podemos ver nestes dados, existe uma desigualdade em termos de oferta de instalaçóes de ensino para acomodar os alunos que transitam o ensino primário do $1^{\circ}$ grau para o ensino primário do $2^{\circ}$ grau.

Assim, verifica-se uma base bastante larga de infraestruturas no EP1 e uma estreita no EP2 que de certa forma contribui na evasão escolar de muitas crianças e limita as vagas para os novos ingressos que pela primeira vez pretendem entrar no subsistema. E por isso, em cada ano

3 Resumidamente, podemos dizer que existem 11.742 escolas do EP do $1^{\circ}$ grau que acolhem aproximadamente a 5 milhóes de alunos da $1^{\text {a }}$ a $5^{\text {a }}$ séries contra 76.572 professores do mesmo nível. 
lectivo temos milhôes de crianças que não usufruem o direito à educação consagrada por lei.

Em 2012, o Instituto de Estudos Sociais e Económicos desenvolveu um estudo intitulado "Moçambique e a Explosão Demográfica: Somos Muitos? Somos Poucos?" que faz uma análise para aferir como é que o ritmo de crescimento populacional afecta o processo de desenvolvimento socioeconómico do país. Neste estudo constatou-se que Moçambique tem um ritmo de crescimento cerca de $2,5 \%$ por ano, que corresponde aproximadamente a 700 mil pessoas (FRANCISCO, 2012, p. 57). Portanto, anualmente o Estado consegue construir $14.000^{4}$ salas do EP e 200 para o ensino secundário.

$\mathrm{O}$ ritmo de crescimento da população constitui um risco inviabilizador do projeto educativo porque não é acompanhado no sector da educação por medidas estruturais eficazes em termos de construção de escolas e, por isso, cerca de 70 mil alunos estudam ao relento (céu aberto ou ar livre) e, no Plano Económico Social 2015-2019 fez-se a previsão de a construir de 1.027 salas de aulas (MOÇAMBIQUE, 2015, p. 34). Esta medida prevista no Plano Económico Social não resolve o problema da insuficiência de infraestruturas escolares.

Segundo o Relatório Anual do Desenvolvimento Humano do Programa das Naçóes Unidas para o Desenvolvimento, existem grandes disparidades no acesso do ensino primário entre as diferentes províncias, derivadas das limitações de oferta de lugares no sistema (PNUD, 2000, p. 34).

Esta disparidade revela que, a expansão das infraestruturas escolares do ensino básico pode ser lenta do que o forte crescimento demográfico da população estudantil e por isso estimou-se que em 2011, 93\% da população escolarizável dos 6 aos 12 anos de idade frequenta o ensino primário contra $88 \%$ em 2007 . No entanto, o ideal era que se atingisse $100 \%$ nas taxas de escolarização, mas isso não aconteceu.

Para resolver o problema dos alunos que estudam nas salas "ar livre", o Governo necessita por ano de 34 mil salas e cada sala de aula custaria em média 706 mil meticais ${ }^{5}$, totalizando 23 mil milhôes de meticais ou 800 milhôes de dólares americanos para a construção das 34 mil salas de aulas. Esse valor representa quase todo o bolo orçamental do ano que o estado aloca ao Sector da Educação.

Portanto, na altura as maiores províncias com salas edificadas na base de material precário $^{6}$, destacavam-se em primeiro lugar a província de Nampula com 60\%, Cabo Delgado 55\%, Zambézia 54\% e finalmente Inhambane com 52\% (CASTIANO E NGOENHA, 2013, p. 54).

\section{Rácio professor/alunos no sistema de educaçáo moçambicana}

Um outro desafio imposto ao sistema nacional de educação moçambicana, é a questão do Rácio Professor/Aluno. E, para responder a demanda no sentido da oferta no acesso do ensino básico, que resultou no aumento do número de alunos, foram contratados professores, disponibilizados os livros escolares, materiais didáticos e reforçou-se o apoio financeiro direto para as escolas.

4 De toda a despesa para o investimento no sector, apenas $25 \%$ é que vai para a construçáo de salas de aulas.

5 O metical é uma unidade monetária oficial de Moçambique, foi instituído no país em 16 de julho de 1980 e substituiu entâo moeda colonial, escudo português.

64 45 de salas de aulas no país são de construção precária (o Jornal O País, 2014, p. 10). 
Segundo Programa estratégico de educação (PEE) de 2012 à 2016, o rácio professor/ aluno no ensino básico reduziu de 75 em 2006 para 63 em 2011 porque houve um crescimento significativo no recrutamento de novos professores e operou-se uma melhoria no sistema de gestão dos recursos humanos, o que possibilitou a verificação dos professores que por diversos motivos abandonaram a carreira e foram substituídos (MINED, 2012, p. 57). Houve, portanto de 2006 para 2011 uma redução do rácio professor/aluno em 12\%.

O atual rácio é de 1 professor para 70 alunos no subsistema do ensino básico e isto revela ainda problemas estruturais sérios, porque os professores continuam poucos para tantos alunos, fato que sobrecarrega os professores e consequentemente compromete a qualidade do ensino. Este rácio, mesmo apesar dos esforços do Sector da Educação para reverter a situação, continua ainda muito acima do máximo recomendável ou ideal. A média ideal é de 1 professor para 30 alunos. O que significa que, esta cifra atual está duas vezes acima do limite.

Conforme dados publicados no Jornal "O País" o número de professores no EP1 aumentou de 66.160 em 2010 para 76.572, uma evolução de mais de 13,6\% em 2014 . No ensino primário do segundo grau, em 2010, o efetivo de professores era de 21,590, o qual subiu para 24.549 em 2014, o que representa um acréscimo de mais de 12\% (JORNAL O PAÍS, 2014, p. 10).

Os fatores que contribuíram na redução do rácio professor/aluno, em alguns anos como nos referimos anteriormente, foi o incremento na contratação de docentes do ensino primário e a reforma do sistema de gestão dos recursos humanos. E ainda um outro fator não menos importante, é a construção acelerada de escolas e salas de aulas, o que permite minimizar o problema da superlotação nas salas de aulas.

O compromisso do Sector da Educação para o quinquénio 2015-2019 prevê contratar uma média de 8.400 professores por ano, na sua maioria para o ensino primário, com vista a reduzir o elevado rácio professor/aluno, do atual rácio de 1 professor para 63 alunos, para 57 alunos para cada professor (MOÇAMBIQUE, 2015, p. 60-63).

Se a média de contratação de novos professores manter 8.400 por ano, significa que até ao final de 5 anos (fim do mandato governo atual), 42 mil novos professores vão entrar no quadro do Sector da Educação. Estes dados revelam que o país ainda não colmatou o problema da insuficiência de professores, uma vez que o número da população continua a aumentar significativamente.

Na concepção da aposta do Governo moçambicano para o Sector da Educação básica assente na expansão da rede escolar e da oferta do ensino de qualidade, que antes ficou reduzido drasticamente devido à guerra civil, e não foi elaborado um plano paralelo para os níveis subsequentes, o secundário e o pré-universitário, de forma a prepará-lo para receber os graduados das novas escolas básicas.

As taxas de reprovação massiva no ensino básico constituem um indicador da ineficiência do sistema. Estas merecem uma análise pormenorizada pois, para além da preocupação em formar todas as crianças sem discriminação, este facto obriga o Governo a despender recursos que não tem, para acomodar e educar as crianças que não chegaram a concluir os ciclos de formação no tempo previsto. Portanto, este facto tem como consequência no aumento do rácio professor/aluno. 
Um das razões do fraco desempenho das crianças no ensino básico é o elevado número de alunos por turma. Quando se analisa o número médio de alunos por turma, observa-se que o aproveitamento é baixo e, este afecta de forma negativa a qualidade do ensino porque o professor não tem como fazer uma assistência individualizada e atenciosa.

Se por exemplo, uma turma tem 70 alunos e o professor tem quatro turmas, é com muita dificuldade que este professor irá atingir os seus objetivos, entre eles melhorar a qualidade de ensino plasmado no PEE 2012-2016.

O nível de exigência por vezes é inadequado porque implica o redobrar de esforços por parte do professor, porque mesmo que este tenha vontade de faze-lo, teria dificuldades em manter o esforço durante o ano todo e é por isso que, os alunos acumulam dificuldades e arrastam deficiências durante a frequência do ensino primário, transitam com elas e ingressam ainda com elas nos níveis subsequentes, o que é por si só, o prenúncio de uma formação deficiente.

\section{Qualidade de ensino no ensino básico sistema de educaçáo moçambicana}

A necessidade de melhorar a qualidade do ensino básico constitui atualmente o centro do debate político e social, consequentemente um enorme desafio. A percepção da comunidade no geral é que a qualidade oferecida nas escolas do ensino básico é fraca e o sector da educação tem envidado esforços em busca de melhores estratégias para solucionar o problema.

No que concerne à melhoria da qualidade, as açóes definidas no PEE 2012 incidem na necessidade de:

a) Continuar a produção e a distribuição do livro escolar, assegurando a sua racionalização para a inclusão do livro no ensino bilingue, bem como de livros de leitura complementar para estimular a cultura de leitura e compra de livros em braile para os deficientes visuais; b) Dar continuidade a revisão do currículo, tendo em conta o reforço das áreas de leitura, escrita e cálculo numérico em termos de competência definidas por ciclo de aprendizagem; c) A prioridade do ensino primário é reformar a formação e capacitação de professores através da introdução, com base num projeto-piloto do novo modelo de formação inicial dos professores, garantindo uma componente prática na sala de aulas e a introdução de aspectos de gestão escolar (MINED, 2012, p. 67-69).

Embora se tenham verificado progressos na distribuição de grandes quantidades de livro (manuais didáticos) após a introdução do novo currículo do ensino básico em 2004, permanecem ainda muitos constrangimentos. Os livros escolares fornecidos pelo Governo tendem a chegar muito tarde devido à morosidade na logística de distribuição e transporte para zonas recônditas e, são frequentes os desvios para o mercado informal. E, aliado a isso, verifica-se a falta de capacidade de compra por parte dos pais e/ou encarregados de educação.

Os livros são fornecidos gratuitamente por ministério de educação para as crianças da $1^{\text {a }}$ a $7^{\mathrm{a}}$ séries com base na projeção do número de matrículas. De acordo com a UNICEF, em 2007, $53 \%$ das crianças da $6^{a}$ séries tinham uso exclusivo de um livro de leitura e 14\% partilhavam um livro com um colega de turma, enquanto que $25 \%$ partilhavam um livro com dois ou mais colegas. Não havia livros disponíveis em 8\% das salas de aulas da $6^{a}$ série (UNICEF, 2011, p. 122).

Devido ao crescimento da rede escolar, o ministério de educação contrata anualmente 
mais pessoas sem formação para leccionarem nas escolas primárias. Por exemplo, conforme Castiano e Ngoenha (2013), "em 2001 existia um total de 7.175 professores (dos quais 1,253 são mulheres) que, tendo concluído somente a $7^{a}$ classe, foram contratados para darem aulas no ensino básico, sem terem passado por uma formação" (p. 182).

Ainda persiste professores do ensino primário sem a formação psicopedagógica, num país que conta com 40 instituiçóes de formação de professores. O sistema de educação no seu funcionamento normal deveria graduar por ano 4.000 professores, mas, nos últimos anos, somente gradua em média 1.600 professores para o nível primário. Isto significa que, há um défice anual de cerca de 2.400 professores e que são contratadas pessoas sem formação para as várias escolas primárias no país para cobrir o défice.

Estes professores com baixa formação profissional ou sem a formação mostram competências deficientes para a implementação do currículo, ou seja, "os professores manifestam dificuldades na implementação dos programas de ensino devido à falta de formação de algumas disciplinas novas" (MINED, 2014, p.7).

No debate da qualidade coloca-se em questão primeiramente o desempenho e a qualificação do professor. Observando a realidade, pode-se aferir, com base em juízos empíricos que, em muitas escolas, principalmente nas zonas rurais, existe um grande número de professores sem formação ou qualificação pedagógica mínima. Estes são colocados face aos alunos sem o auxílio necessário, oferecendo uma qualidade de preparação de aulas nas séries iniciais muito fraca.

Inicialmente, a melhoria da qualidade do ensino estava ligada ao apetrechamento das escolas e repartições administrativas das escolas básicas por meios humanos e materiais, ou seja, a tese sustentada era de que alocando fundos financeiros a escolas, a formação dos professores e pagamento dos seus salários se teria a qualidade desejada.

Nota-se nesta ordem de ideia e conforme Castiano e Ngoenha (2013), o enfoque do Governo era mais ou menos economicista sobre a qualidade da educação ${ }^{7} \mathrm{O}$ princípio fundamental da visão economicista da educação é que quanto mais dinheiro investido nas atividades educativas, melhor seria a qualidade dos serviços oferecidos.

Portanto, num período posterior, a tese baseada no financiamento das atividades educativas, é substituída por uma abordagem de eficácia do processo. Esta mudança de paradigma justifica-se dado que o Governo e a sociedade, depois de injetarem mais recursos para o sector da educação, passam a exigir mais eficácia na utilização dos recursos e que mostrem resultados do processo de Ensino-Aprendizagem. É por este motivo que a sociedade começa a pôr em causa a legitimidade da qualidade da educação oferecida aos alunos, e surgem novos padrôes de gestão e garantia de qualidade como elevadas taxas de retenção, maiores taxas de aprovação dos alunos e rendimentos escolares.

\section{Consideraçóes finais}

A tendência do debate sobre políticas ligadas a educação básica tem defendido que uma

7 Esta é uma política formulada pelo Banco Mundial, nas suas políticas educacionais. Tommasi refere que a política educativa proposto pelo Banco Mundial, é um modelo essencialmente escolar e caracterizado por duas grandes ausências: os professores e a pedagogia. Assim, a educação passa a ser analisada com critérios próprios do mercado e a escola é comparada a uma empresa (TOMMASI et al, 2000, p.138 a 140). 
boa qualidade de educação infere-se pelo grau de satisfação dos alunos, da família, comunidade e das instituiçóes em relação ao desempenho da escola, ou seja, se os alunos têm adquirido competências exigidas no plano curricular do ensino básico, no que concerne a leitura, escrita e o cálculo.

O primeiro indicador de qualidade de ensino que se questiona nos debates é o desempenho e a qualificação dos professores porque a maioria não tem a formação ou qualificação psicopedagógica mínima, oferecendo uma qualidade de preparação de aulas muito fraca.

E o segundo, chamado ao debate sobre a qualidade do ensino básico é a situação das instalaçóes escolares inadequadas e insuficiência de materiais didáticos. No que concerne a escola, o ambiente institucional que reina não é propício para a aprendizagem porque as condiçôes das infraestruturas são precárias e a falta de um processo democrático na gestão e administração escolar, o que cria um conflito entre a direção e o corpo docente (verifica-se a perda da autoridade do professor). Este ambiente nefasto de organização do ensino e da aprendizagem, concorre para a fraca qualidade.

Neste contexto, devido à subjetividade que o termo qualidade abarca, esta deve ser entendida na sua acepção de desempenho escolar. Segundo MINED, no seu Relatório Preliminar da Avaliaçâo Nacional Sobre a Aprendizagem, indica que o desempenho dos alunos é baixo, dado que perto de $80 \%$ dos alunos são capazes de reconhecer as convençóes do sistema alfabético, contudo o nível de apropriação é atingido por sensivelmente $44 \%$ dos alunos e apenas $6 \%$ atingem o nível desejado, portanto são capazes de ler palavras, frases e textos simples, (MINED, 2014). Contudo, um outro fator não menos importante da qualidade da educação básica que constitui desafio, é a qualidade externa do aluno, ou seja, a eficácia externa do ensino.

O sistema de educação em Moçambique tem uma das suas características oferecer uma formação muito genérica. Mas, em contrapartida, a estrutura social do mercado do emprego e os imperativos do desenvolvimento socioeconómico exigem para que a educação esteja voltada ao saber-fazer do que ao saber-conhecer, isso constitui um desafio, e náo menos importante o ensino básico tem outros desafios como: a insuficiência no provimento de professores; inadaptação dos currículos às atuais necessidades do mercado de trabalho, e orçamentos insuficientes, de desistência de alunos nas escolas.

É preciso criar um sistema que não seja discriminatória e nem elitista. Mas, para tal dever haver maior capacidade de dialogo entre os agentes e atores do sistema nacional de educação moçambicana e é preciso um ajustamento de políticas educativas e que o compromisso com a massificação tem que continuar na pauta (política), sem descurar o investimento no ensino básico que pode possibilitar acesso epistémico.

\section{Referências}

CHICAVA, A.k.A. Políticas e desafios da educação técnico-profissional em Moçambique. Revista Impulso, Piracicaba, vol. 28, nº87, p. 87-106, Set-dez, 2018.

CASTIANO, José P. \& NGOENHA, Severino. A Longa Marcha duma Educaçáo para Todos em Moçambique. Maputo, Imprensa Universitária, 3ª ed. 2013. 
Psicopedagógica. 27 de Agosto de 2015, 20:15h.

DUARTE. Stela Mihtá, et al. O discurso sobre qualidade nas políticas educativas em Moçambique - caso do ensino básico (1975-2015). Revista Síntese, Maputo, vol. 8, nº15, p. 41-55, Out-Dez, 2019.

FRANCISCO, António. Moçambique e a Explosão Demográfica: Somos Muitos? Somos Poucos? Maputo, Ideias, $n^{\circ}$ 45, p. 303-307, 2012.

ONU. Relatório sobre os Objectivos de Desenvolvimento do Milénio. Nova Iorque, 2013.

MINED. O informe da revisáo pontual do currículo do ensino primário: aprimorar a gestáo do SNE é garantir a melhoria da qualidade da educaçáo. Maputo, Ed. INDE/ MINED, 2014.

MINED. Plano Curricular do ensino básico: Objectivos, Política, Estrutura, Plano de Estudos e Estratégias de Implementação. Maputo, INDE/MINED, 2003.

MINED. Plano Estratégico da Educação: Desempenho do setor da educação de 2013. Maputo, INDE/MINED, 2014.

MINED. Plano Estratégico da Educaçáo 2012-2016: Construindo competências para um Moçambique em constante desenvolvimento. Maputo, MINED, 2012.

MINED. Evoluçáo do Sistema Educativo 2010-2014: Progressos e Desafios na Implementação do Programa do Governo na Área de Educação. Maputo, INDE/MINED 2014.

MINED. Política Nacional da Educação e Estratégias de Implementação. Maputo, IND/ MINED, 1995.

MOÇAMBIQUE. Boletim da República, Lei no18/2018, I Série, no 254 . Lei do Sistema Nacional de Educaçáo. Maputo, Imprensa Nacional, 2018.

MOÇAMBIQUE. Boletim da República, I Série, n 12 de 23 de Março. Lei do Sistema Nacional de Educaçáo. Maputo, Imprensa Nacional, 1983.

MOÇAMBIQUE. Boletim da República. I Série, n 19 de 06 de Maio. Reajusta o quadro geral do Sistema Educativo. Maputo, Imprensa Nacional, 1992.

MOÇAMBIQUE. Plano Económico e Social 2013. Maputo: 2012.

MOÇAMBIQUE. Programa Quinquenal do Governo 2015-2019. Aprovado pela Resolução nº12/2015, de 14 de Abril, da Assembleia da República, publicado no Boletim da República no 29, 10 Série, 2o Suplemento, Maputo: 2015.

ONU. Relatório sobre os Objectivos de Desenvolvimento do Milénio. Nova Iorque, 2013.

PNUD. Relatório de desenvolvimento humano de 2000. Nova Iorque, 2000.

TOMMASI, Livia et al. O Banco Mundial e as Políticas Educacionais. São Paulo, Cortez, 2000 .

UNICEF. Pobreza Infantil e Disparidade em Moçambique 2010. Maputo, 2011. 